\title{
Influence of time-dependent restrained strains in the shear response of $R C$ frames
}

\section{Denise Ferreira, Jesús M. Bairán \& Antonio Marí}

\section{Materials and Structures}

ISSN 1359-5997

Volume 50

Number 1

Mater Struct (2017) 50:1-17

DOI 10.1617/s11527-016-0875-8

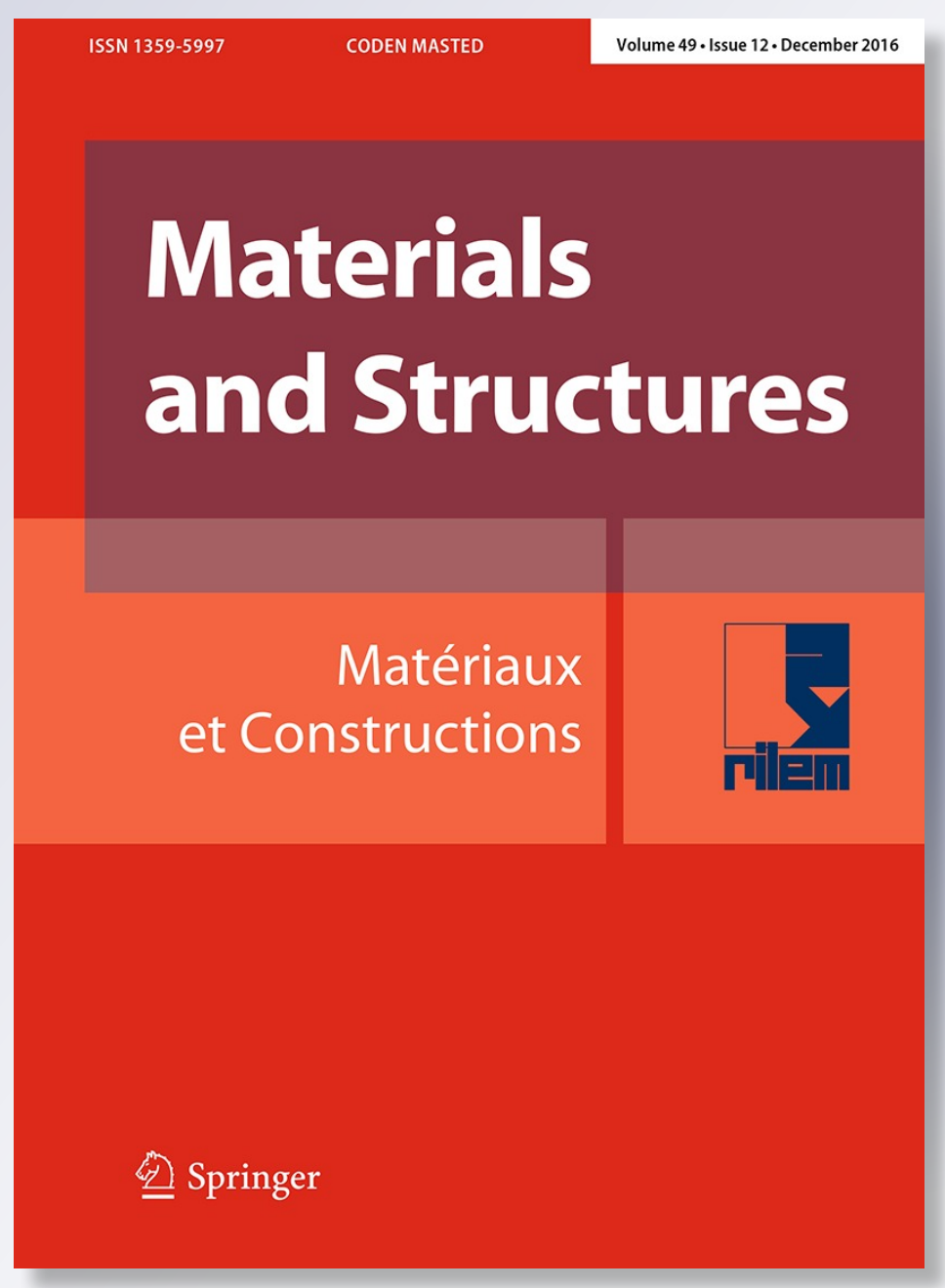

勿 Springer 
Your article is protected by copyright and all rights are held exclusively by RILEM. This eoffprint is for personal use only and shall not be self-archived in electronic repositories. If you wish to self-archive your article, please use the accepted manuscript version for posting on your own website. You may further deposit the accepted manuscript version in any repository, provided it is only made publicly available 12 months after official publication or later and provided acknowledgement is given to the original source of publication and a link is inserted to the published article on Springer's website. The link must be accompanied by the following text: "The final publication is available at link.springer.com". 


\title{
Influence of time-dependent restrained strains in the shear response of $\mathrm{RC}$ frames
}

\author{
Denise Ferreira · Jesús M. Bairán · Antonio Marí
}

Received: 7 January 2016/ Accepted: 16 April 2016

(C) RILEM 2016

\begin{abstract}
Time-dependent strains, when restrained, can lead to important tensile forces and damage, affecting, among other aspects, the shear response and ultimate load carrying capacity of shear-critical RC frames. This paper presents a detailed study of this problematic by means of an extension of a shearsensitive fibre beam model to time dependent behaviour of concrete. The model is firstly validated with experimental tests on diagonally pre-cracked beams under sustained loads. From these analyses, the contributions of shear distortions and bending curvatures to the total long-term deflection of the beams are discerned. Afterwards, the model is applied to study the influence of restraining strains due to long-term creep and shrinkage in the service and ultimate shear response of frames. In contrast with flexural resistant mechanisms, delayed strains may influence the latter shear resistance of integral structures by reducing the concrete contribution to shear resistance and leading to a sooner activation of the transversal reinforcement.
\end{abstract}

D. Ferreira $(\varangle) \cdot$ J. M. Bairán · A. Marí

Department of Civil and Environmental Engineering, ETSECCPB - Universitat Politècnica de Catalunya (UPC), Barcelona TECH, Campus Nord, C/Jordi Girona 1-3, Mod C1, 08034 Barcelona, Spain e-mail: denise.carina.santos@upc.edu

J. M. Bairán

e-mail: jesus.miguel.bairan@upc.edu

A. Marí

e-mail: antonio.mari@upc.edu
These aspects can be relevant in assessing existing structures and this model, due to its relative simplicity, can be advantageous for practical applications.

Keywords Reinforced concrete - Shear - Timedependent deformations $\cdot$ Restraining stresses $\cdot$ Fibre beam model $\cdot$ Nonlinear analysis - Delayed tensileshear interaction $\cdot$ Integral structures

\section{Introduction}

Concrete structures show a complex behaviour that includes material nonlinearities (cracking of concrete, yielding of reinforcement) and time-dependent response (creep, shrinkage, ageing). Both types of phenomena interact in the structural response, e.g.: the existence of cracking increases the compression stresses and creep; and shrinkage can lead to cracking of concrete. In the case of structural members mainly loaded in bending, the coupling of nonlinear and timedependent phenomena was successfully studied in the past [1-3]. However, for the case of structural members critical to shear, the interaction between diagonal cracking, delayed strains and resistant mechanisms is not well known. This interaction can be relevant in service and ultimate limit states. In fact, one the one hand, diagonal cracking can affect the time-dependent strains and creep response and, on the other hand, restrained shrinkage can reduce the shear capacity. 
Pertaining to ultimate limit states, analytical models for shear capacity are usually set as a combination of contributions of concrete $\left(V_{\mathrm{c}}\right)$ and transversal reinforcement $\left(V_{\mathrm{s}}\right)$ [4]. Axial forces (compression and tension) influence the shear strength of $\mathrm{RC}$ elements [5]. Hence, in contrast to the case of bending, delayed axial-shear force interaction induced by restraining time-dependent strains affects the concrete contribution, and consequently the ultimate shear capacity. This problem is also relevant in prestressed elements; where the axial force introduced by the prestressing influences the shear resistance of prestressed concrete beams [6]. As creep and shrinkage decrease the prestressing force with time, resistance to shear also decreases (which may be balanced by the gain of concrete strength with age). This is completely different from the case of bending, in which creep and shrinkage also affects the prestressing force, but have no influence in the ultimate resistance of the beams failing in a ductile mechanism.

Shear resistance in reinforced concrete (RC) involves different contributing actions, leading to state-dependent distributions of shear strains and stresses. The numerical simulation of this mechanism requires models able to reproduce phenomena, such as, diagonal cracking, anisotropic responses and brittle failures. Finite element (FE) models, based on plane stress and solid continuum approaches, are usually used in academia to study small scale specimens; however these models are time consuming, require fine FE meshes and can therefore hardly be applied at the true structural scale.

On the other hand, frame models constitute an efficient alternative to solids FE's, with much less degrees of freedom, while model generation is simpler and faster [7]. These models, which were traditionally limited to bending analysis [2], were extended to include shear and multiaxial force interactions $[8,9]$, as well as, other aspects of RC behaviour (e.g. forceinteraction, material degradation, strengthening with new materials and bond-slip), generating enhanced beam models; e.g. Mazars et al. [10]; Valipour and Foster [11].

The complexity of the shear response in RC makes its numerical simulation and introduction into fibre beam models to be quite challenging $[8,9]$. Pioneer works in this field are attributed to Vecchio and Collins [12], Spacone et al. [13] and Petrangeli et al. [14]. More recently, proposals for accounting for shear-flexural interaction in fibre beam models focused on increasing accuracy and computational efficiency; some relevant examples are Güner [15] and Mohr et al. [16] differing in the level of complexity and applicability. A shear sensitive fibre beam model was developed by the authors [17], covering nonlinear axial-bending-shear ( $\mathrm{N}-\mathrm{M}-\mathrm{V})$ interaction and segmental construction, including the effects of strengthening and repair interventions [18]. The model was applied to the assessment and strengthening analysis of true-scale structures, as bridges [7].

This paper studies the influence of the delayed deformations in the shear-related response of structures. For this purpose, the shear beam model was extended for time-dependent analysis including concrete creep, shrinkage and temperature variations.

Shear modelling involves multiaxial strain-stress states that have to be considered in the timedependent analysis. Extensive experimental research and development of numerical models have mainly been conducted on the uniaxial case [19, 20]. The principle of superposition and the Poisson's ratio resulting from creep of concrete under multiaxial stress states is rather controversial, either by difficulties of measuring and the variability on the experimental devices and also due to the many parameters influencing its behaviour. The non-validity of the superposition assumption for the cases of biaxial stresses is supported by some authors [21, 22]; other authors argue that the multiaxial creep Poisson's ratio varies with time and does not depend on the stress states [23].

The assumption that creep of concrete under multiaxial stresses can be satisfactorily predicted in practice by assuming a constant Poisson's ratio equal to the elastic value, along with a theoretical model for creep under uniaxial stresses is also sustained [23-26]. This simplification is assumed in the proposed model, which is justified by the structural approach of the target simulations.

At the structural level, most studies on shear behaviour have been conducted on isolated elements on isostatic static schemes, allowing free deformation to occur. When analysing large continuous structures, relevant doubts exist in engineering community whether induced stresses, strains and previously developed damage (e.g. rheological induced cracks) produce differences in the resisting behaviour. Studies about this problem are scant. 
In this paper, a study is conducted in order to address this problematic based on the shear frame model previously developed by the authors. The model was adapted to include creep and shrinkage capabilities in a multiaxial format for the frame element. After presentation of the formulation, the model is validated against experimental tests on shearsensitive beams under sustained load. Subsequently, the model is used to study the details of the influence of delayed tension-shear forces interaction and restrained strains in the ultimate shear strength of $\mathrm{RC}$ frames. These studies aim to investigate the effects of rheological strains and its previously induced damage in the shear resisting behaviour of continuous concrete elements.

\section{Numerical model}

The detailed description and validation of the nontransient version of the shear-sensitive fibre beam model can be found in [17]. This section presents only the fundamentals of the basis shear model and focus on the time-dependent procedures.

\subsection{Fundamentals of the shear-sensitive fibre beam model}

The model is based on a displacement-based fibre beam FE formulation for the nonlinear analysis of concrete frame structures. The fundamental assumptions of the model are: (i) RC frames are idealized by means of beam elements of arbitrary cross sections interconnected by nodes; (ii) the cross section is discretized into fibres of concrete and filaments of longitudinal steel; (iii) transversal reinforcement is accounted as smeared in the concrete fibre; (iv) for each FE, the longitudinal reinforcement is considered parallel to the longitudinal axis; (v) the Timoshenko beam theory is applied at the element level; (vi) at the sectional level, a shear-sensitive formulation accounts for the axial force-bending-shear (N-M-V) interaction: the Bernoulli-Navier plane-section theory is coupled with a constant shear stress constraint along the cross section leading to a $2 \mathrm{D}$ strain-stress state in the fibres.

A smeared and rotating crack approach is considered for concrete. The Hognestad parabola is assumed for concrete in compression as the backbone curve.
The determination of the various parameters of this curve (ultimate strength $f_{\mathrm{c}}$, strain at peak stress $\varepsilon_{0}$, ultimate strain $\varepsilon_{\mathrm{u}}$ ) account for lateral effects: softening [27] and strength enhancement [28] factors. For concrete in tension a linear response is assumed before cracking and a tension stiffening curve is considered in the cracked stage. A modified version of the exponential tension stiffening curve of [29] is used, being calibrated so that it produces null stiffening for beyond yielding of steel [17]. Steel is only submitted to axial strains and stresses by means of uniaxial constitutive laws (defined by the yielding stress $f_{\text {sy }}$ and strain $\varepsilon_{\text {sy }}$ and the ultimate stress $f_{\text {su }}$ and strain $\varepsilon_{\text {su }}$ ). Perfect bond between concrete and steel reinforcements is assumed.

\subsection{Time-dependent constitutive model for concrete}

Creep is a stress dependent strain, although it is not instantaneous, and can be computed by two modelling approaches: (i) include it as part of the response of a visco-elastic material and (ii) referring to mechanical strain only to the strains related to the instantaneous stresses $\left(\Delta \varepsilon^{m}=D^{-1} \Delta \sigma\right)$ and considering all delayed strains (including creep) as a free strain.

In the first option, creep should be considered as part of the mechanical strains, which requires computing both displacement and velocities in the iteration scheme.

In the second option, creep similarly to other free strains, in general do not satisfy compatibility, thus unbalanced forces will develop in time without variation of forces which activates the Newton-Raphson iteration process in order to preserve equilibrium, as used by Kabir and Scordelis [30], Kang and Scordelis [31] and Mari [2]. Therefore, together with the equilibrium conditions, this approach will produce equivalent results to the visco-elastic material formulation. This second approach is the one followed in this paper.

Time-dependent effects of concrete creep and shrinkage are taken into account in the shear fibre beam model through a biaxial formulation within a time-step procedure based on the work of [3].

Within the time domain, an incremental step-bystep method is used to compute the non-mechanical strains. Each component of strain is determined separately and summed afterwards by assuming valid the principle of superposition of strains. Creep and 
shrinkage are treated in a decoupled manner. The effects of temperature variations are also considered in an independent fashion. Coupling between cracking and time-dependent strains [32] is not considered, for the sake of simplicity of the model devised for structural applications; and also because capturing beam failures under sustained loads and at high stress levels is not a goal of this study.

Non-mechanical strains accounts for strain offsets, different from instantaneous strains produced by stresses increments in the current time step. In the context of this work, it includes both shrinkage and creep strains. Even though creep strains are actually stress dependent, they are related to the previously applied stresses, not the increment on the current timestep. Therefore, they can be considered as strain offsets, provided that the iteration process accounts for compatibility and equilibrium conditions, producing similar results as considering creep as stress dependent, after convergence. The 2D non-mechanical strain vector $\Delta \underline{\varepsilon}^{n m}$ depends on time $t$ and is divided into two types of strains: stress-dependent $\Delta \underline{\varepsilon}^{\mathrm{c}}$ and stress-independent $\Delta \underline{\varepsilon}^{0}$ (in incremental approach),

$\Delta \underline{\varepsilon}^{n m}(t)=\Delta \underline{\varepsilon}^{\mathrm{c}}(t)+\Delta \underline{\varepsilon}^{0}(t)$

The strain tensor of creep $\Delta \underline{\varepsilon}$ is stress-dependent,

$\Delta \underline{\varepsilon}^{\mathrm{c}}(t)=\left\{\begin{array}{c}\Delta \varepsilon_{x}^{\mathrm{c}} \\ \Delta \varepsilon_{z}^{\mathrm{c}} \\ \Delta \gamma_{x z}^{\mathrm{c}}\end{array}\right\}$

The tensors of strains due to shrinkage and temperature variations, considered as stress-independent, are treated as volume changes $\Delta \varepsilon^{0}$, and for this reason, do not contemplate shear deformations, as in Chong et al. [33]:

$\Delta \underline{\varepsilon}^{0}(t)=\left\{\begin{array}{l}\Delta \varepsilon_{x}^{0} \\ \Delta \varepsilon_{z}^{0} \\ 0\end{array}\right\}=\left\{\begin{array}{l}\Delta \varepsilon_{x}^{\mathrm{sh}} \\ \Delta \varepsilon_{z}^{\mathrm{sh}} \\ 0\end{array}\right\}+\left\{\begin{array}{l}\Delta \varepsilon_{x}^{\mathrm{T}} \\ \Delta \varepsilon_{z}^{\mathrm{T}} \\ 0\end{array}\right\}$

\subsubsection{Creep}

The principle of superposition of creep strains is assumed valid, as the strains are considered small. The principles of isotropy and linearity are assumed valid as well, as considered in [24].

In this model it is considered that, while performing the time integration with a small time step, the stress state does not vary within the time step. It should be noticed that different assumptions may be considered depending on the integration scheme. However, as creep evolves slowly in time, different evolution hypotheses will not produce significant variations. The creep response in compression and tension is assumed equal before cracking; after cracking no creep strain is considered in tension.

The incremental strain tensor in concrete due to creep $\Delta \underline{\varepsilon}^{\mathrm{c}}$ is given by the constitutive relationship for aging material under multiaxial stress for a given instant of time $t$ :

$\Delta \underline{\varepsilon}^{\mathrm{c}}(t)=\int_{0}^{t} B_{\mathrm{e}} J\left(t^{\prime}, t-t^{\prime}, T\right) \frac{\partial \underline{\sigma}\left(t^{\prime}\right)}{\partial t^{\prime}} d t^{\prime}$

in which specifically for the $2 \mathrm{D}$ case, comes:

$\Delta \underline{\varepsilon}^{\mathrm{c}}(t)=\left(\Delta \varepsilon_{x}^{\mathrm{c}}, \Delta \varepsilon_{z}^{\mathrm{c}}, \Delta \gamma_{x z}^{\mathrm{c}}\right)^{T}$

$\Delta \underline{\sigma}(t)=\left(\Delta \sigma_{x}, \Delta \sigma_{z}, \Delta \sigma_{x z}\right)^{T}$

$B_{\mathrm{e}}=\left(\begin{array}{ccc}1 & -v_{\mathrm{c}} & 0 \\ -v_{\mathrm{c}} & 1 & 0 \\ 0 & 0 & 2\left(1+v_{\mathrm{c}}\right)\end{array}\right)$

where $\Delta \underline{\sigma}$ is the incremental stress tensor and $B_{\mathrm{e}} J$ is the compliance matrix in which the creep compliance function $J\left(t^{\prime}, t-t^{\prime}, T\right)$ depends on the concrete age at the moment of loading $t^{\prime}$ and the temperature $T$. Justified by the focus of this model on the structural level, the creep Poisson ratio $v_{c}$ under biaxial stresses is assumed constant and equal to the elastic value.

Based on the formulation derived by [34], the biaxial creep strain tensor given by the integral of Eq. (4) is determined through a fitted series of Dirichlet as

$J\left(t^{\prime}, t-t^{\prime}, T\right) \approx \sum_{i=1}^{m} a_{i}\left(t^{\prime}\right)\left[1-e^{-\lambda_{i} \varphi(T)\left(t-t^{\prime}\right)}\right]$

where $a_{i}$ are the scale factors that depend on the age of loading $t^{\prime}$ and $\lambda_{i}$ are retardation time constants that govern the shape of the logarithmic decaying creep curve, $\varphi(T)$ is the temperature shift function that depends on the temperature, $t$ is the considered time and $m$ are the number the series of Dirichlet used to approximate the compliance function [2]. The defining parameters are determined by applying the least square method to a creep empirical expression. In the analysis presented in this paper the expression 
proposed by Model Code 1990 (MC-90) [35] is used; which is justified by the fact that the model that is in the basis of this work [2] used this expressions. The empirical curves were not updated to more recent ones in order to ensure a direct comparison between the two models. Also, considering the main goal of this work-evaluate the influence of time-dependent strains in the nonlinear shear structural responseMC90 expressions are acceptable and will not affect the main conclusions related to shear behavior.

The approximation of the Dirichlet series is performed by means of the hidden variables formulation [34]; constants $\lambda_{i}$ set as $10^{-i}\left(\lambda_{1}=0.1\right.$, $\left.\lambda_{2}=0.01 ; \lambda_{3}=0.001\right)$ and 3 series are considered $(m=3)$, which does not require the storage of all previous stress states for the determination of the creep strain increment in a time step. The algorithm used to compute creep strains through a Dirichlet series is described in detail in Annex A.

\subsubsection{Stress-independent strains}

Biaxial shrinkage strain $\Delta \underline{\varepsilon}^{\text {sh }}$ is given by the vector of stress-independent volume changes:

$\Delta \underline{\varepsilon}^{\mathrm{sh}}(t)=\left(\Delta \varepsilon_{x}^{\mathrm{sh}}, \Delta \varepsilon_{z}^{\mathrm{sh}}, 0\right)^{\mathrm{T}}$

In the analysis presented in the paper, the MC-90 code [35] function for the total shrinkage strains, i.e. including both autogenous and drying shrinkage, is used to compute the increment of shrinkage strain as:

$\Delta \varepsilon_{x}^{\mathrm{sh}}=\varepsilon_{\mathrm{cs} 0} \beta_{\mathrm{s}}\left(t-t_{\mathrm{s}}\right) ; \Delta \varepsilon_{z}^{\mathrm{sh}}=\varepsilon_{\mathrm{cs} 0} \beta_{\mathrm{s}}\left(t-t_{\mathrm{s}}\right)$

in which $t_{\mathrm{s}}$ is the age of concrete at the start of shrinkage; $\varepsilon_{\mathrm{cs} 0}$ is the notional shrinkage coefficient that is a function of the compressive strength of concrete, of the cement type and of the environmental relative humidity; $\beta_{\mathrm{s}}$ is the coefficient that describes the development of shrinkage with time and depends on the dimensions of the cross-section of the element.

Effects of temperature variations are accounted for by means of the stress independent strain vector $\Delta \underline{\varepsilon}^{\mathrm{T}}$ :

$\Delta \varepsilon^{\mathrm{T}}(t)=\alpha\left(T_{n}-T_{n-1}\right)\left[\begin{array}{l}1 \\ 1 \\ 0\end{array}\right]$

through the coefficient of thermal dilatation of concrete $\alpha$ and the differences of temperature $T$ between the time steps $n$ and $n-1$.
2.3 Formulation to account for shear and timedependent effects

In the shear-sensitive sectional model, the plane section theory is coupled with a shear stress constraint, and the determination of the fibre state is performed using a hybrid stress-strain input parameters. For each fibre, given the axial strain in concrete $\varepsilon_{x}$ and the assumed shear stress $\tau^{*}=V / A$, and using the equilibrium, compatibility and constitutive equations, the strain and stress states and the stiffness of the fibre are determined. Details about the formulation can be found in [17].

The constitutive model is formulated in terms of average principal strains $\varepsilon_{12}=\left[\begin{array}{ll}\varepsilon_{1} & \varepsilon_{2}\end{array}\right]^{\mathrm{T}}$ and average principal stresses $\underline{\sigma}_{12}=\left[\begin{array}{ll}\sigma_{1} & \sigma_{2}\end{array}\right]^{\mathrm{T}}$, in which the principal directions of the strain and stress tensors are assumed to be coincident. In the principal referential axes, the 2D stress-strain state can be written as

$\left\{\begin{array}{l}\sigma_{1} \\ \sigma_{2} \\ \tau_{12}\end{array}\right\}=D_{12}\left\{\begin{array}{l}\varepsilon_{1} \\ \varepsilon_{2} \\ \gamma_{12}\end{array}\right\} ; \quad D_{12}=\left(\begin{array}{ccc}E_{1} & 0 & 0 \\ 0 & E_{2} & 0 \\ 0 & 0 & G_{12}\end{array}\right)$

$G_{12}=\frac{1}{2} \frac{\sigma_{1}-\sigma_{2}}{\varepsilon_{1}-\varepsilon_{2}}$

where $E_{1}$ and $E_{2}$ are the stiffness modulus in each principal direction and $G_{12}$ is the co-rotational transversal modulus [36].

Transversal steel is considered smeared through its volumetric ratio $\rho_{\mathrm{st}}$ and is submitted to axial stresses $\sigma_{z}^{\text {st }}$ (along direction $z$ ). The increment of axial stresses in the transversal reinforcement $\Delta \sigma_{z}^{\text {st }}$ is computed as

$$
\begin{aligned}
& \left(\begin{array}{l}
0 \\
\Delta \sigma_{z} \\
0
\end{array}\right)^{\mathrm{st}}=D_{\mathrm{st}}\left(\begin{array}{l}
0 \\
\Delta \varepsilon_{z} \\
0
\end{array}\right) ; \\
& D_{\mathrm{st}}=\left(\begin{array}{lll}
0 & 0 & 0 \\
0 & \rho_{\mathrm{st}} E_{\mathrm{st}} & 0 \\
0 & 0 & 0
\end{array}\right) ; \\
& \rho_{\mathrm{st}} E_{\mathrm{st}}=\sum_{k=1}^{n_{k}}\left(\frac{A_{\mathrm{st}, k}}{s_{k} b_{k}} E_{\mathrm{st}, k}\right)
\end{aligned}
$$

where $E_{\mathrm{st}}$ is the elasticity modulus of steel; as the cross section can have different configurations of stirrups, $A_{\mathrm{st}, k}$ is the area of transversal steel $b_{k}$ is the width of the 
cross-section and $s_{k}$ is the longitudinal spacing of each configuration $k$ (for more details see Ferreira et al. [18]). Compatibility requirements impose that the vertical strain in concrete and the strain in the transversal reinforcement are equal, being denoted as $\varepsilon_{z}$. No bond slip is considered. The stiffness matrix of the fibre $D_{\text {fibre }}$ is given by the summation of contributions of concrete and transversal reinforcement, upon rotation to the local $x-z$ referential system,

$$
\begin{aligned}
& \left(\begin{array}{c}
\Delta \sigma_{x} \\
\Delta \sigma_{z} \\
\Delta \tau_{x z}
\end{array}\right)=D_{\text {fibre }}\left(\begin{array}{c}
\Delta \varepsilon_{x} \\
\Delta \varepsilon_{z} \\
\Delta \gamma_{x z}
\end{array}\right) \\
& D_{\text {fibre }}=\left(\begin{array}{lll}
D_{11} & D_{12} & D_{13} \\
D_{21} & \bar{D}_{22} & D_{23} \\
D_{31} & D_{32} & D_{33}
\end{array}\right) \\
& \bar{D}_{22}=D_{22}+\rho_{\mathrm{st}} E_{\mathrm{st}}
\end{aligned}
$$

The determination of the state of the fibre (condensed stiffness matrix $K_{\text {fibre }}$ and internal resistant force $\underline{S}_{\text {fibre }}$ ) is presented in the following sections, including the effects of the non-mechanical strains due to the time-dependent effects.

The contribution of the fibres to the sectional stiffness matrix $K_{\mathrm{sec}}$ and internal force vector $\underline{S}_{\mathrm{sec}}$ are determined by the integration of stiffness and forces of all the fibres of the cross section, as:

$$
\begin{aligned}
K_{\text {sec }}^{\mathrm{c}+\mathrm{st}} & =\int_{A} T^{\mathrm{T}} K_{\text {fibre }} T d A \\
\underline{S}_{\text {sec }}^{\mathrm{c}+\mathrm{st}} & =\int_{A} T^{\mathrm{T}} \underline{S}_{\text {fibre }} d A
\end{aligned}
$$

where $A$ is the area of each fibre and $T$ is the Timoshenko transformation matrix that relates the generalized strains of the element to the strains in each fibre.

Longitudinal steel is considered under axial strainstress state. The contribution of the longitudinal reinforcement for the cross-section can be computed as the integral of stiffness and stresses throughout all the filaments as:

$$
\begin{aligned}
& K_{\mathrm{sec}}^{\mathrm{sl}}=\int_{A_{\mathrm{sl}}} T_{\mathrm{sl}}^{\mathrm{T}} E^{\mathrm{sl}} T_{\mathrm{sl}} d A_{\mathrm{sl}} \\
& \underline{S}_{\mathrm{sec}}^{\mathrm{sl}}=\int_{A_{\mathrm{sl}}} T_{\mathrm{sl}}^{\mathrm{T}} \sigma_{x}^{\mathrm{sl}} d A_{\mathrm{sl}}
\end{aligned}
$$

where $A_{\mathrm{sl}}$ is the area of each steel filament and $T_{\mathrm{sl}}$ is the transformation matrix related to the plane section theory.

The element used is a 2-node Timoshenko FE with linear shape functions. The determination of the element stiffness matrix $K_{\text {elem }}$ and the internal resistant load vector $F_{\text {elem }}$ use the sectional formulations formerly described:

$$
\begin{aligned}
& K_{\text {elem }}=\int_{L} B K_{\mathrm{sec}} B d x \\
& \underline{F}_{\text {elem }}=\int_{L} B^{T} \underline{S}_{\mathrm{sec}} d x
\end{aligned}
$$

These integrals are solved through the Gaussian Quadrature Method and reduced integration is considered in order to avoid shear locking. The nonlinear FE model is implemented into a Newton-Raphson (NR) framework in order to solve the global equations of equilibrium.

\subsubsection{Basic fibre state determination}

In order to determine the state of each fibre, two requirements have to be fulfilled: (i) equilibrium in the transversal direction between the concrete and the vertical reinforcement, given by:

$$
\Delta \sigma_{z}^{c}+\rho_{\mathrm{st}} \Delta \sigma_{z}^{\mathrm{st}}=0 \quad \rho_{\mathrm{st}} \Delta \sigma_{z}^{\mathrm{st}}=\sum_{k=1}^{n_{k}}\left(\frac{A_{\mathrm{st}, k}}{s_{k} b_{k}} \Delta \sigma_{z, k}^{\mathrm{st}}\right)
$$

and (ii) the computed increment of shear stress $\Delta \tau_{x z}$ must equate the imposed shear stress given by the fixed stress constraint $\Delta \tau *$ :

$\Delta \tau^{*}-\Delta \tau_{x z}=0$

Considering the system of these two equations and making use of the Eq. (15) and after mathematical handling, the increments of vertical axial strain $\Delta \varepsilon_{z}$ and shear strain $\Delta \gamma_{x z}$ are given by:

$$
\begin{aligned}
\Delta \varepsilon_{z}= & \frac{\left(D_{23} D_{31}-D_{33} D_{21}\right) \Delta \varepsilon_{x}-D_{23} \Delta \tau^{*}}{D_{33} \overline{D_{22}}-D_{23} D_{32}} \\
\Delta \gamma_{x z} & =\frac{\overline{D_{22}} \Delta \tau^{*}+\left(D_{32} D_{21}-D_{31} \overline{D_{22}}\right) \Delta \varepsilon_{x}}{\left(D_{33} \overline{D_{22}}-D_{23} D_{32}\right)}
\end{aligned}
$$


being functions of the increments of the longitudinal axial strain $\Delta \varepsilon_{x}$, the shear stress $\Delta \tau^{*}$ and the material stiffness matrix $D_{\text {fibre }}$. This determination is not linear and an iterative procedure within the fibre level is needed; for more details see [17].

After convergence is achieved and the requirements at the fibre level are verified, a static condensation of Eq. (15) is performed in order to eliminate the elements related with the vertical direction $\left(\Delta \sigma_{z}\right.$, $\Delta \varepsilon_{z}$ ) that are not included in the sectional formulation, resulting into the following expressions:

$$
\begin{aligned}
\Delta S_{\text {fibre }} & =K_{\text {fibre }}\left\{\begin{array}{c}
\Delta \varepsilon_{x} \\
\Delta \gamma_{x z}
\end{array}\right\} \\
K_{\text {fibre }}= & \left(\begin{array}{ll}
D_{11}-\frac{D_{12} D_{21}}{\bar{D}_{22}} & D_{13}-\frac{D_{12} D_{23}}{\bar{D}_{22}} \\
D_{31}-\frac{D_{32} D_{21}}{\bar{D}_{22}} & D_{33}-\frac{D_{32} D_{23}}{\bar{D}_{22}}
\end{array}\right) \\
= & {\left[\begin{array}{ll}
D_{11}^{*} & D_{13}^{*} \\
D_{31}^{*} & D_{33}^{*}
\end{array}\right] } \\
\Delta S_{\text {fibre }}= & \left(\begin{array}{c}
\Delta \sigma_{x} \\
\Delta \tau_{x z}
\end{array}\right)
\end{aligned}
$$

where $K_{\text {fibre }}$ is the condensed stiffness matrix and $S_{\text {fibre }}$ is the internal resistant force vector of the fibre.

\subsubsection{Inclusion of the time-dependent effects}

The time of the analysis is divided into time steps. During a time-step, the structural response is determined through the initial strain approach derived by [37] and also used by [2,3]. Load is applied at time $t_{n}$ and is kept constant along the time step $\Delta t_{n}$. At each time instant $t$, the increment of the total strain vector in a fibre $\Delta \varepsilon_{\varepsilon}^{t}(t)$ is given by the sum of the mechanical $\Delta \varepsilon^{m}(t)$ and the nonmechanical strain $\Delta \varepsilon^{n m}(t)$ vectors Eq. (1).

The non-mechanical biaxial strain vector in each fibre is given by the summation of the different contributions (creep $\Delta \underline{\varepsilon}^{\mathrm{c}}$, shrinkage $\Delta \underline{\varepsilon}^{\text {sh }}$ and thermal gradients $\left.\Delta \underline{\varepsilon}^{\mathrm{T}}\right)$ as:

$$
\Delta \underline{\varepsilon}^{n m}(t)=\Delta \underline{\varepsilon}^{\mathrm{c}}(t)+\Delta \underline{\varepsilon}^{\mathrm{sh}}(t)+\Delta \underline{\varepsilon}^{\mathrm{T}}(t)
$$

The incremental form of the equivalent nodal force vector in the element due to non-mechanical strains $\Delta F_{\text {elem }}^{n m}$ is given by the expression of the Finite Element Method (FEM):
$\underline{\Delta F}_{\text {elem }}^{n m}=\int_{V} T^{\mathrm{T}} D \underline{\Delta \varepsilon}^{n m} d V$

However, accordingly to the proposed shear fibre beam model, the element equivalent force vector due to non-mechanical strains $\Delta \underline{F}_{\text {elem }}^{n m}$ is computed in the incremental form through the use of the sectional equivalent force vector $\Delta \underline{S}_{\mathrm{sec}}^{n m}$ (integration domain is the element length $(L)$ and reduced gauss integration is used in the 2-nodes FE, that means one gauss point located at the middle of each element):

$\underline{\Delta}_{\mathrm{elem}}^{n m}=\int_{L} T^{\mathrm{T}} \underline{\Delta S_{\mathrm{sec}}^{n m}} d x$

where $T$ is the Timoshenko transformation matrix and the extended formats of increment of equivalent load force and non-mechanical strain vectors are:

$\underline{\Delta S}_{\mathrm{sec}}^{n m}=\left[\begin{array}{c}c \Delta N \\ \Delta V_{z} \\ \Delta M_{y}\end{array}\right]^{n m}$

$\underline{\Delta \varepsilon}^{n m}=\left[\begin{array}{c}\Delta \varepsilon_{x} \\ \Delta \gamma_{x z} \\ \Delta \phi_{y}\end{array}\right]^{n m}$

The sectional equivalent force vector due to nonmechanical strains $\Delta \underline{S}_{-}^{n m}$ elem, which includes concrete and the smeared transversal reinforcement, is given as

$$
\underline{\Delta S}_{\mathrm{sec}}^{n m}=\int T^{T} \underline{\Delta S}_{\text {fiber }}^{n m} d A
$$

In each fibre, as the concrete and stirrups are in equilibrium in the vertical direction and consequently the resultant vertical stresses are null, the equivalent internal load vector due to initial strains $\Delta \underline{S}_{\text {fibre }}^{n m}$ is computed incrementally by means of the condensed constitutive matrix of the fibre presented in Eq. (27).

$$
\begin{gathered}
\Delta \underline{S}_{\text {fibre }}^{n m}=K_{\text {fibre }} \Delta \underline{\varepsilon}^{n m} \\
\Delta S_{\text {fibre }}^{n m}=\left(\begin{array}{c}
\Delta \sigma_{x}^{n m} \\
\Delta \tau_{x z}^{n m}
\end{array}\right) \\
K_{\text {fibre }}=\left[\begin{array}{ll}
D_{11}^{*} & D_{13}^{*} \\
D_{31}^{*} & D_{33}^{*}
\end{array}\right] \\
\Delta \underline{\varepsilon}^{n m}=\left(\begin{array}{c}
\Delta \varepsilon_{x}^{n m} \\
\Delta \gamma_{x z}^{n m}
\end{array}\right)
\end{gathered}
$$


As presented in the previous point, the input variables needed to perform the fibre state determination are the mechanical longitudinal strain and the shear stress:

$\left\{\begin{array}{l}\Delta \varepsilon_{x}^{t}(z)=\Delta \varepsilon_{0}+\Delta \phi_{y} \cdot z \\ \Delta \tau^{*}=G^{*} A^{*} \Delta \gamma_{0}\end{array}\right.$

In the presence of non-mechanical strains, these input equations are re-written as:

$\left\{\begin{array}{l}\varepsilon_{x}^{m}(z)=\Delta \varepsilon_{x}^{t}-\Delta \varepsilon_{x}^{n m} \\ \Delta \tau^{*}=G^{*} A^{*} \Delta \gamma_{0}\end{array}\right.$

On the one hand, in these entering assumptions, non-mechanical strains are only taken into account in the longitudinal direction $\Delta \varepsilon_{x}^{n m}$; in fact, as a consequence of the hypothesis assumed by the shear fibre beam model, neither the vertical $\Delta \varepsilon_{z}^{n m}$ nor the transversal non-mechanical strains $\Delta \gamma_{x z}^{n m}$ are accounted in this stage. On the other hand, the outputted mechanical strains at the fibre level (the vertical $\Delta \varepsilon_{z}$ and distortion $\Delta \gamma_{x z}$ strains determined respectively in Eq. (24) and Eq. (25) are computed, in an incremental form, as functions of the mechanical longitudinal strain $\Delta \varepsilon_{x}^{m}$, imposed tangential stress $\Delta \tau^{*}$ and the current stiffness matrix of the fibre $D_{\text {fibre: }}$ :

$\left\{\begin{array}{l}\Delta \varepsilon_{z}^{m}=f\left(\Delta \varepsilon_{x}^{m}, \Delta \tau^{*}, D_{\text {fibre }}\right) \\ \Delta \gamma_{x z}^{m}=f\left(\Delta \varepsilon_{x}^{m}, \Delta \tau^{*}, D_{\text {fibre }}\right)\end{array}\right.$

In order to compute the total incremental strains, the non-mechanical strains are added to the correspondent outputted mechanical strains as:

$\left\{\begin{array}{c}\Delta \varepsilon_{z}^{t}=\Delta \varepsilon_{z}^{m}+\Delta \varepsilon_{z}^{n m *} \\ \Delta \gamma_{x z}^{t}=\Delta \gamma_{x z}^{m}+\Delta \gamma_{x z}^{n m}\end{array}\right.$

Note that, in the z-direction, $\Delta \varepsilon_{z}^{n m^{*}}$ is not directly given by the non-mechanical strain $\Delta \varepsilon_{z}^{n m}$, actually, the presence of transversal reinforcement do not allow for the free deformation of the concrete in this direction. In order to take into account the restraining effects to the imposed deformations brought by the presence of stirrups, the equilibrium in the z-direction given by Eq. (22) is re-written as:

$\Delta \sigma_{z}^{c}+\rho_{\mathrm{st}} \Delta \sigma_{z}^{\mathrm{st}}=D^{*} \Delta \varepsilon_{z}^{n m}$

or, in terms of strains, as:
$D_{c} \Delta \varepsilon_{z}+\rho_{\mathrm{st}} E_{\mathrm{st}} \Delta \varepsilon_{z}=D^{*} \Delta \varepsilon_{z}^{n m}$

resulting into the following expression for the nonmechanical strains in the vertical direction including the restraining effects of the transversal reinforcement in the fibre:

$\Delta \varepsilon_{z}^{n m *}=\frac{D_{\mathrm{c}}}{D_{\mathrm{c}}+\rho_{\mathrm{st}} E_{\mathrm{st}}} \Delta \varepsilon_{z}^{n m}=\frac{1}{1+n \rho_{\mathrm{st}}} \Delta \varepsilon_{z}^{n m} ; n=\frac{E_{\mathrm{st}}}{D_{\mathrm{c}}}$

in which the stiffness of concrete $D_{\mathrm{c}}$ is given by the element $D_{22}$ of the stiffness matrix of the concrete fibre, $E_{\text {st }}$ and $\rho_{\text {st }}$ corresponds, respectively, to the elasticity modulus and the volume ratio of transversal steel.

\subsection{Finite element implementation}

In the time-dependent analysis the period of time is divided into time steps, and the non-mechanical strains are continuously updated. Pertaining to the computation of strains, a step-forward integration scheme in the time domain is performed by continuously adding the results obtained at each previous time step, as adopted in [2]. The response of a structure during a time step is determined through the initial strain approach previously described.

The increment of non-mechanical strains $\Delta \underline{\varepsilon}^{n m}$ that occurs during the time interval $\Delta t_{n}$ is given by the summation of the different contributions (creep $\Delta \varepsilon^{\mathrm{c}}$, shrinkage $\Delta \varepsilon^{\text {sh }}$ and thermal gradients $\left.\Delta \varepsilon^{T}\right)$. Afterwards, the equivalent nodal force vector in the element due to the non-mechanical strains $\Delta \underline{F}_{\text {elem }}^{n m}$ is determined. This load vector is assembled into the structural equivalent load vector. Load is then applied at time $t_{n}$ and is kept constant for the time step $\Delta t_{n}$. A Newton-Raphson procedure is used to find the solution of the global equilibrium equations.

\section{Simulation of the beam tests by Nie and Cai}

\subsection{Description}

Experimental tests on diagonally cracked beams under sustained load were performed by Nie and Cai [38]. The goal of this experimental campaign was to assess the contribution of shear deformations to the longterm deflection of $\mathrm{RC}$ beams. The specimens were 
designed to develop both flexural and diagonal cracking under service load levels. In order to determine the load level to apply in the long-term tests that ensured significant diagonal cracking, instant loading tests were carried out previously in analogous specimens. By these means, the sustained load applied in the long-term tests was chosen as the correspondent load causing diagonal cracking of $0.2-0.3 \mathrm{~mm}$ of width.

The beams are simple supported with a total length of $2.78 \mathrm{~m}$ and a distance between supports of $2.18 \mathrm{~m}$. The cross section is of rectangular shape with $0.2 \mathrm{~m}$ width and $0.4 \mathrm{~m}$ high. The beams have longitudinal (two rows of three rebars) and transversal (two-branch stirrups) reinforcement. The beams were tested under two-point loading with a shear-span ratio of 2.5; each point load located at a distance of $0.85 \mathrm{~m}$ from the support.

From all the specimens tested, those with vertical transversal reinforcement were considered for simulation, whose characteristics are listed in Table 1 . The general information about the applied loads and correspondent diagonal crack widths are included in Table 1 . The analysed beams differ from each other in the ratios of longitudinal $\rho_{\mathrm{s} 1}$ and transversal $\rho_{\mathrm{st}}$ reinforcement and in the concrete strength $f_{\mathrm{c}}{ }^{\prime}$. The duration of the long-term tests were of 3 months and the mid-span deflection data is available. Average temperatures were of $28.1{ }^{\circ} \mathrm{C}$ for specimens B1-B3 and $17.5^{\circ} \mathrm{C}$ for B5 and B6 and relative humidity of 50.7 and $61 \%$, respectively.

The experimental tests were simulated with the proposed shear model and with the basic flexural model [2]. By comparing both results (Fig. 1a), it is possible to assess the importance of considering shear effects in the prediction of the behaviour of these beams. The mesh used is the same in both numerical models (consisting of 26 FEs of constant length and fibres of $0.005 \mathrm{~m}$ of width) and the reinforcement ratios and material properties considered are those presented in Table 1. Both models include similar creep and shrinkage formulations.

\subsection{Results and discussion}

All the specimens were analysed with the numerical models; however only the results of one beam (B1) are presented here; the other simulations presented similar results and agreement with the experimental data [39]. The experimental deflections at mid-span with time are depicted in Fig. 1a along with the predictions computed by the shear and flexural models. In general, the instantaneous deflection is well predicted by the shear model in contrast to the systematic lesser displacement computed by the flexural model. This difference evidences the significant importance of shear in the behaviour of these specimens. Regarding the general long-term response, acceptable predictions were achieved by the shear model. Figure $1 \mathrm{~b}$ represents the contributions of bending $(\varphi)$ and shear $(\gamma)$ to the total long-term deflection, computed by the proposed shear model. It is observed that shear distortion is significant only in the instantaneous deflection, bringing almost null contribution to the long-term deflection.

\section{Numerical studies on shear critical transfer girders}

\subsection{Time-dependent response under service load}

The classical shear benchmark of Vecchio and Shim [40], beam VSA1, submitted to instantaneous incremental load until failure at the age of 38 days was considered as a reference example in this study. In a

Table 1 Characteristics of the Nie and Cai beam tests

\begin{tabular}{llllllll}
\hline Beam & $\begin{array}{l}\rho_{\mathrm{sl}} \\
(\%)\end{array}$ & $\begin{array}{l}\rho_{\mathrm{st}} \\
(\%)\end{array}$ & $\begin{array}{l}\text { Longitudinal steel } f_{\mathrm{sy}} \\
(\mathrm{MPa})\end{array}$ & $\begin{array}{l}\text { Transversal steel } f_{\text {sy }} \\
(\mathrm{MPa})\end{array}$ & $\begin{array}{l}\text { Concrete } f_{\mathrm{c}}^{\prime} \\
(\mathrm{MPa})\end{array}$ & $\begin{array}{l}\text { Sustained load } \\
(\mathrm{kN})\end{array}$ & $\begin{array}{l}\text { Initial diagonal crack } \\
\text { width }(\mathrm{mm})\end{array}$ \\
\hline B1 & 2.5 & 0.25 & 462 & 293 & 38 & 220 & 0.2 \\
B2 & 3.4 & 0.25 & 462 & 293 & 38 & 210 & 0.2 \\
B3 & 2.5 & 0.50 & 462 & 293 & 38 & 220 & 0.2 \\
B5 & 2.5 & 0.50 & 462 & 293 & 41 & 220 & 0.2 \\
B6 & 2.5 & 0.50 & 462 & 293 & 41 & 260 & 0.3 \\
\hline
\end{tabular}



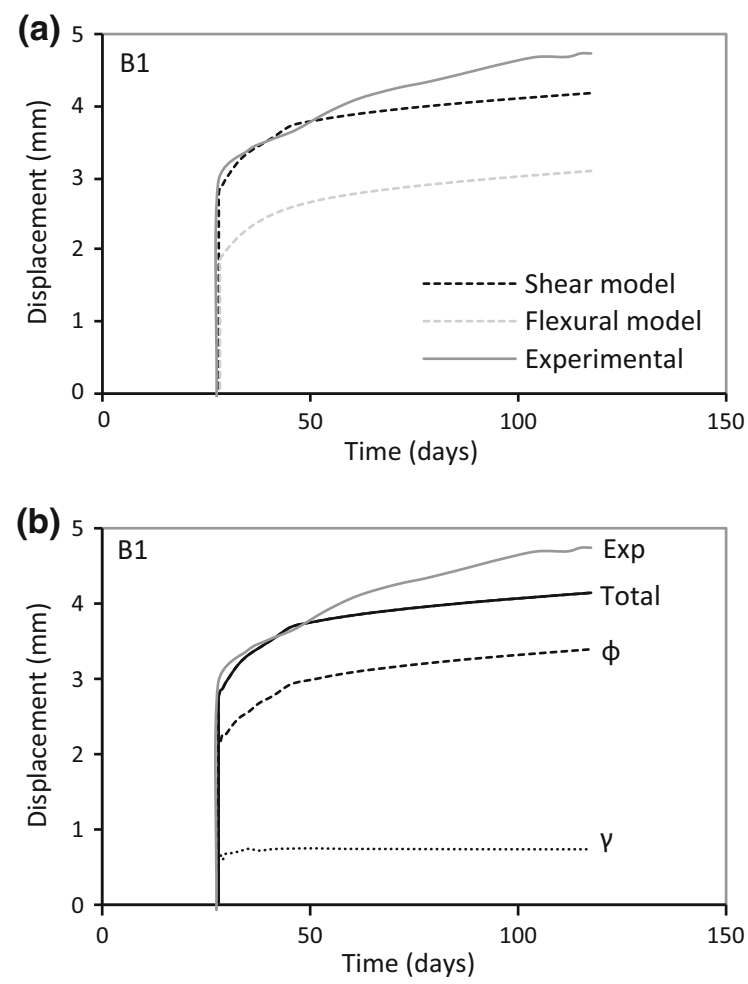

Fig. 1 Deflection at mid span versus time for beam B1: a total displacements and $\mathbf{b}$ contributions of shear and bending

previous work [39], the shear model reproduced correctly this test under instant load, revealing the strong relevance of shear effects in the response. Here, the VSA1 beam is adapted as part of integral structures; theoretical transfer girders with different levels of restraint were considered and simulated with the numerical model.

Two transfer girders (TG) are analysed differing only in the cross section of the columns as represented in Fig. 2. The majority of properties of the original beam VSA1 were maintained: geometry, material properties, loading configuration and transversal reinforcement. The mechanical properties of concrete were as follows: $f_{\mathrm{c}}=22.6 \mathrm{MPa}, f_{\mathrm{ct}}=2.37 \mathrm{MPa}$ and $E_{\mathrm{c}}=36.5 \mathrm{GPa}$. The mechanical properties of the longitudinal steel reinforcement were $f_{\text {sy }}=440 \mathrm{MPa}$ and $E_{\mathrm{s}}=201 \mathrm{GPa}$ for rebars of $25.2 \mathrm{~mm}$ of diameter and $f_{\mathrm{sy}}=436 \mathrm{MPa}$ and $E_{\mathrm{s}}=200 \mathrm{GPa}$ for rebars of $29.9 \mathrm{~mm}$ of diameter. As for the transversal reinforcement, the mechanical steel properties were $f_{\text {sy }}=600$ $\mathrm{MPa}, f_{\mathrm{su}}=649 \mathrm{MPa}$ and $E_{\mathrm{s}}=200 \mathrm{GPa}$.
The negative reinforcement was designed according to the negative moments resulting from the increasing flexure stiffness in the columns. In order to investigate the influence of the stiffness of the restraining element, the columns were simulated through elastic supports at both ends of the beamthe translation $K_{x}$ and rotation stiffness $K_{\theta y}$-determined accordingly to the geometry of the columns (Fig. 2): $E$ is the elasticity modulus of concrete ( $35 \mathrm{GPa}), I$ is the modulus of inertia of the cross section ( $b$ is $0.3 \mathrm{~m}$ and $h$ is $0.3 \mathrm{~m}$ for TG1 and $0.5 \mathrm{~m}$ for TG2) and $L$ is its length (4 m for both girders). Significantly different restraint levels are achieved: TG1 represents small level of restraint, $K_{x}=8859$ $\mathrm{kN} / \mathrm{m}$ and $K_{\theta y}=23,625 \mathrm{kNm} / \mathrm{rad}$ (comparable to a simple supported condition) and TG2 represents higher level of restraint, $K_{x}=41,016 \mathrm{kN} / \mathrm{m}$ and $K_{\theta y}=109,375 \mathrm{kNm} / \mathrm{rad}$ (comparable to a double end fixed condition); TG2 has translation and rotation stiffness 4.6 times higher than TG1.

The girders were loaded until a service load of $P=225 \mathrm{kN}(V=P / 2=112.5 \mathrm{kN})$, corresponding to $49 \%$ of ultimate load [40]. This load was sustained for 4000 days and afterwards the girders were again loaded incrementally until failure. Further analyses were performed without passage of time, with the instantaneous load being applied directly until failure.

In addition to these simulations with the shear model, a parallel set of simulations are also performed with the flexural basic model [2] in order to assess the influence of shear in all these phenomena. Same meshes and material properties were considered in all the analyses.

The effects of cracking will be discussed in the following presentation of results, with damage referring to observable physical damage of cracking of concrete. In that sense, no distinction will be made between cracking and damage in the element. It should be noticed that, although related, the authors do not refer strictly to a damage variable in the sense of a damage constitutive model.

The different responses of the two girders are evident in Fig. 3 where the development of axial force $(N)$ is represented with time. In the flexible girder TG1, axial forces are low and there is a small influence of shear in the response (both models give similar results). In TG2, there are greater axial forces generated by the restraining effects. Development of tensile forces with time caused by the restraining transient 

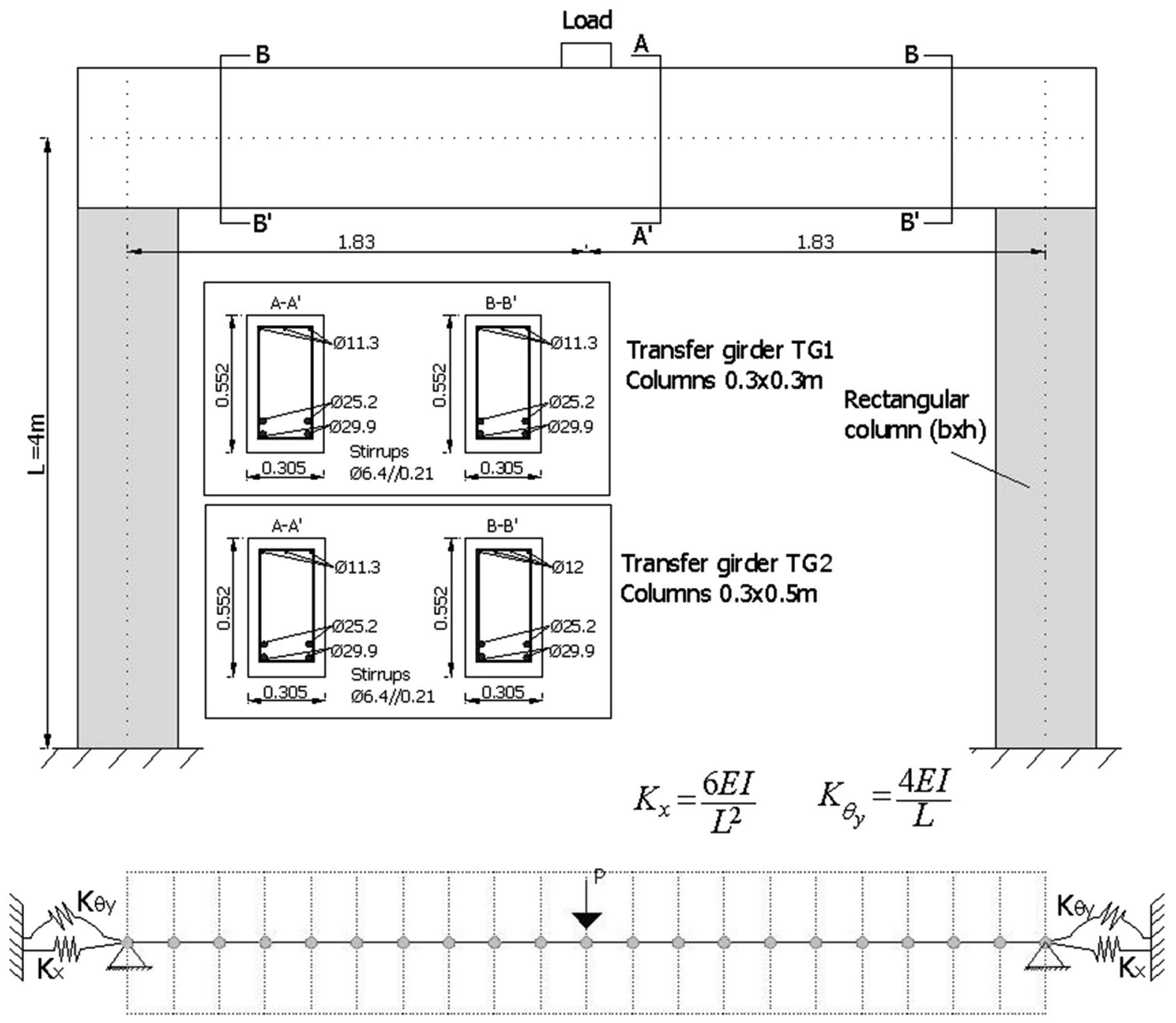

Fig. 2 Characteristics of the transfer girders

strains is higher when shear effects are considered. The inflection point in the shear model around 1500 days reflects the increment of cracking. Shear effects in this case (TG2) increases damage.

Longitudinal strains $\varepsilon_{x}$ and stresses $\sigma_{x}^{\mathrm{c}}$ in concrete along the mid shear span cross section under service load level are depicted in Fig. 4 for $t=0$ and $t=\infty$ and for both models. In general, consideration of shear leads to an increment of curvature of the cross section and an up rise of the neutral axis. TG1 cross section is cracked at the service load level. In the long-term, there is a decrease of compression and tensile stresses which lead to closing of cracks. TG2 presents an opposite response: the cross section is not cracked for $t=0$ and cracks with

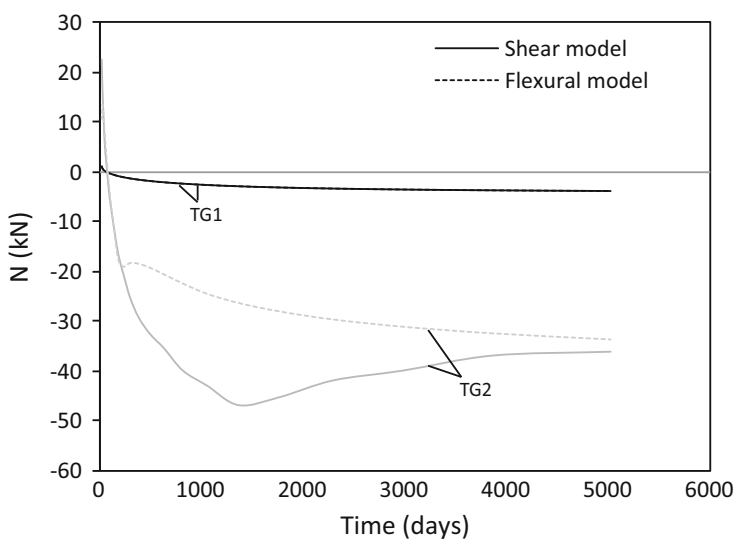

Fig. 3 Variation of axial force in the transfer girders with time 
time due to the restraining strains. Here, the shear model presents more damage than the flexural model, with lower tension stiffening stresses.

\subsection{Behaviour at failure}

After passage of time, the girders are submitted to incremental loading until failure. Longitudinal strains in the transversal reinforcement for $t=\infty$ are represented in Fig. 5 for the mid shear span cross section and for two shear load levels $(V): 112.5 \mathrm{kN}$ (service sustained load) and $175 \mathrm{kN}$ (higher load level). The results of the loading tests performed without time passage are included in these graphs as $t=0$. Only results of the shear model are presented as the flexural model does not consider transversal reinforcement.

For TG1, stirrups are activated right after the application of the load $(V=112.5 \mathrm{kN})$. Under
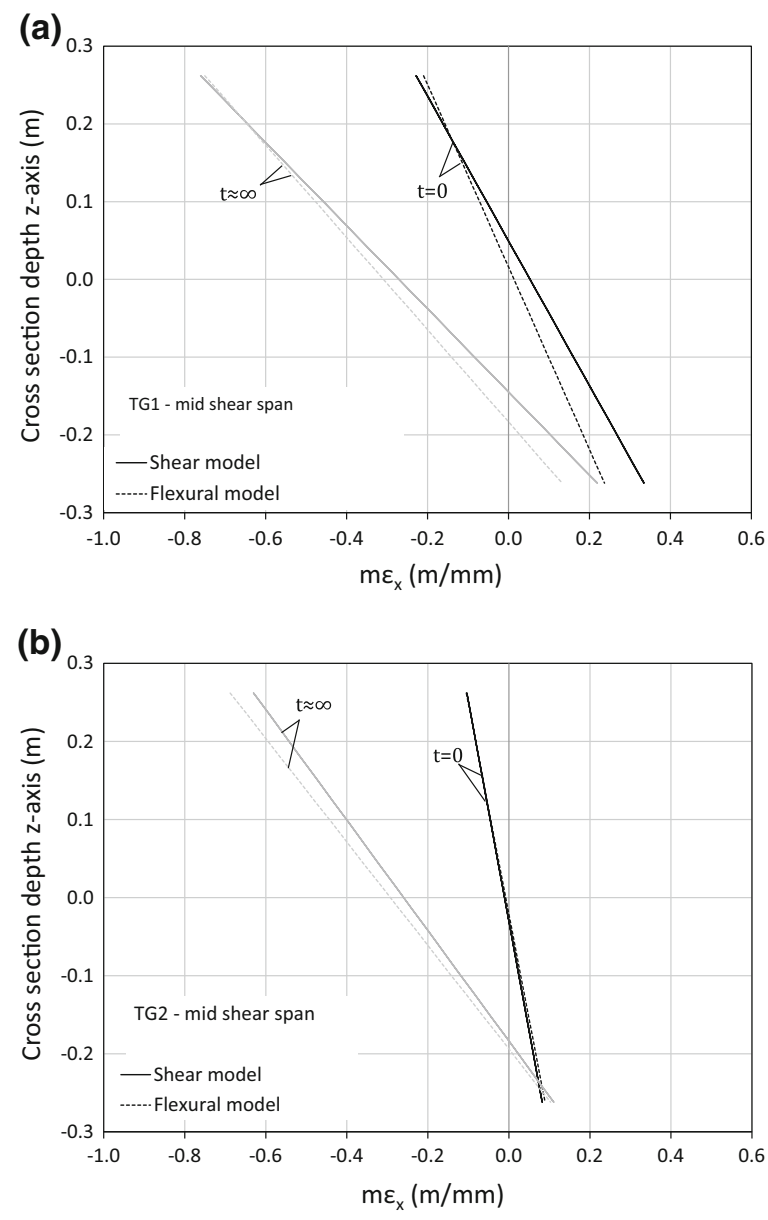

sustained load and for $t=\infty$, a redistribution of forces between concrete and transversal steel is observed, with increasing strains in the stirrups at the bottom of the section and unloading at the upper area. In girder TG2, stirrups are compressed for $t=0$ and are activated for $t=\infty$. Pertaining to the higher load level ( $V=175 \mathrm{kN})$, TG1 presents a strain offset between $t=0$ and $t=\infty$ : long-term analysis $(t=\infty)$ presents greater strains in the stirrups than short-term analysis $(t=0)$. However, this difference is small when compared with the TG2 case. Here, for $V=175 \mathrm{kN}$ stirrups have null strains for $t=0$ and are yielded for $t=\infty$. These results show the development of stirrups strains with time as consequence of restraining shrinkage strains. In fact, in contrast with flexural resisting mechanism, delayed strains may influence the latter shear performance of $\mathrm{RC}$ frames.
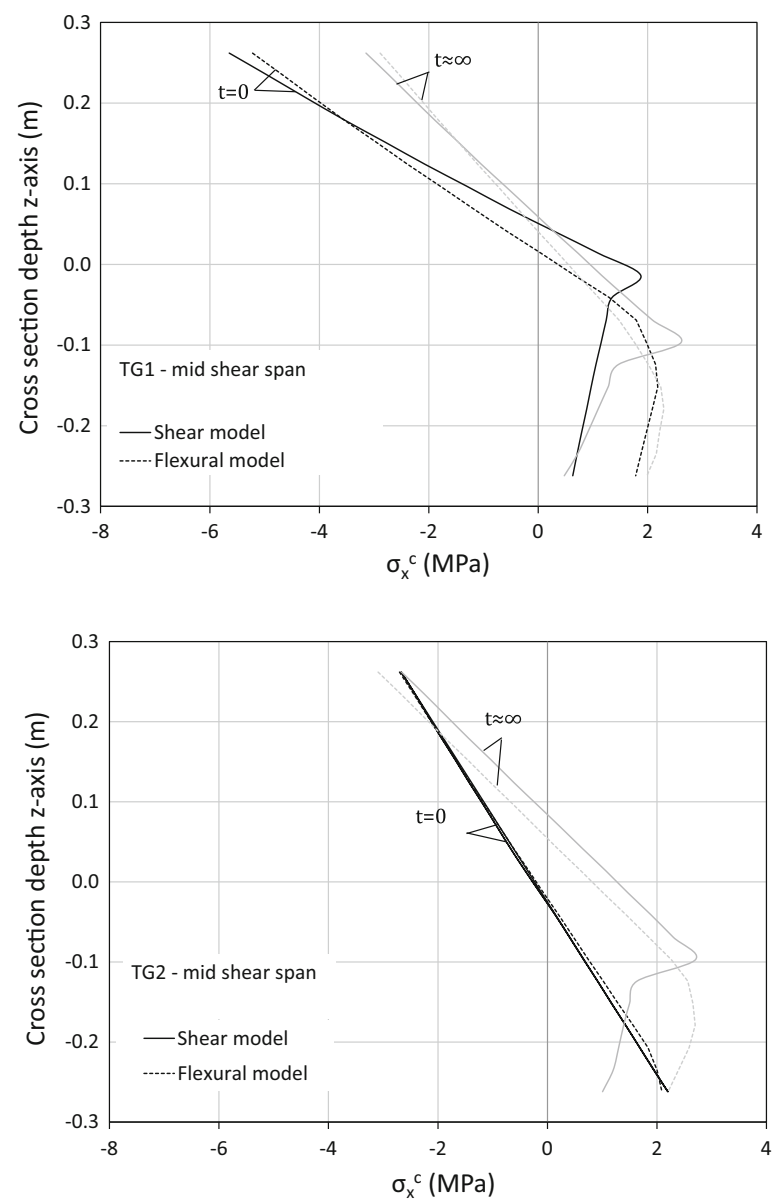

Fig. 4 Strains (left) and stresses (right) in concrete along the height of the mid shear span cross section: a TG1, b TG2

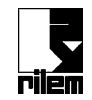



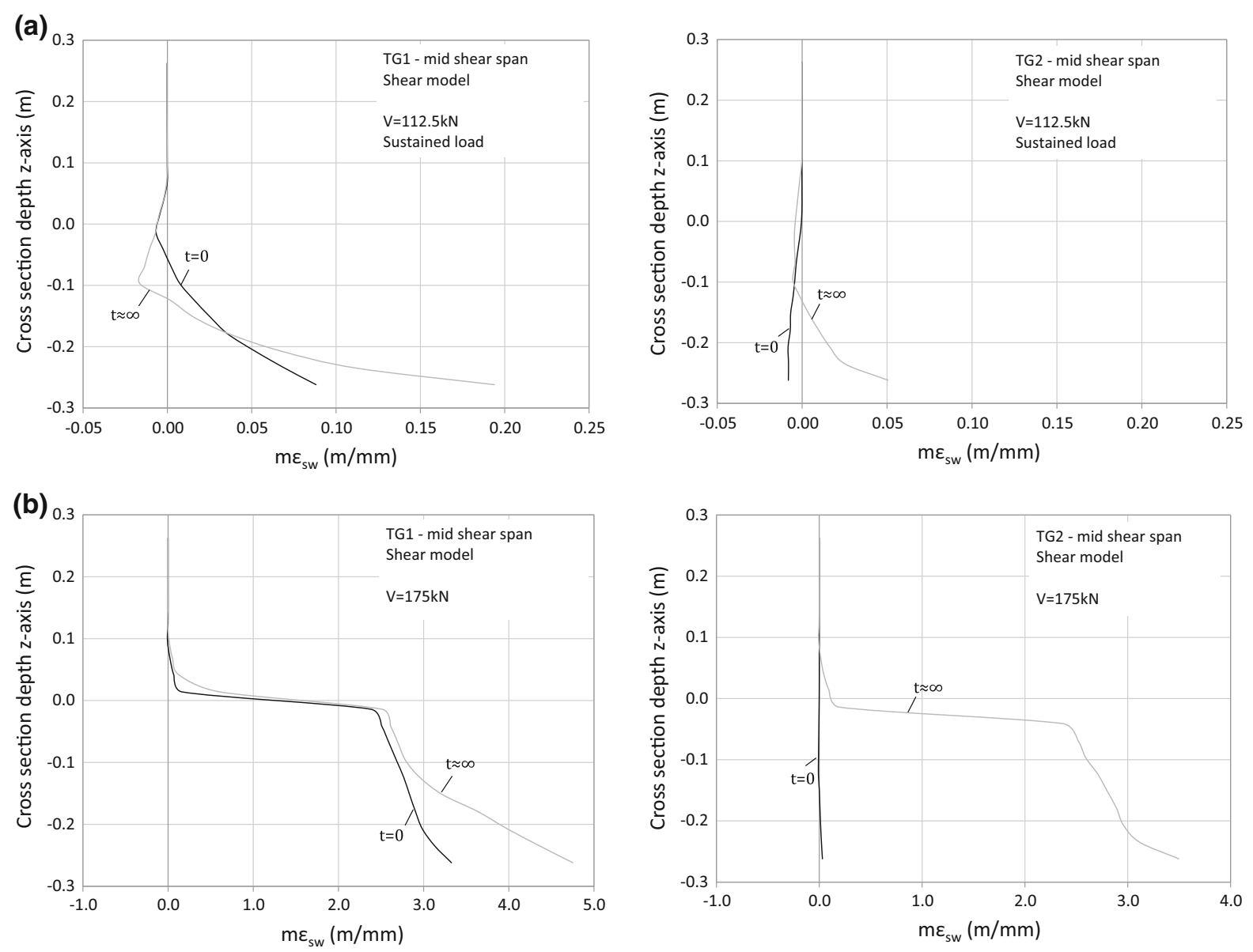

Fig. 5 Strains in transversal reinforcement along the height of the mid shear span cross section of TG1 (left) and TG2 (right): a $V=112.5 \mathrm{kN}$ and $\mathbf{b} V=175 \mathrm{kN}$

This influence is clear when comparing contributions of shear mechanism in Fig. 6 with increasing load for short-term $(t=0)$ and long-term analysis $(t=\infty)$ : $V_{\mathrm{s}}$ is the contribution of transversal reinforcement and is determined by integrating the longitudinal forces in stirrups along the section height (Fig. 5) and $V_{\mathrm{c}}$ is the concrete contribution and corresponds to the load level of cracking initiation and consequent activation of transversal reinforcement. These results also relate to the cross section located at mid shear span. These graphs show how time-dependent restrained strains affect the concrete contribution to shear: $V_{\mathrm{c}, \infty}$ takes smaller values than $V_{\mathrm{c}, 0}$ and this difference is greater for higher levels of restraint.

In other words, the rigid frame TG2 presents more damage due to higher restraining shrinkage strains, resulting into a sooner activation of stirrups and consequent reduction of ultimate shear strength. The yielding of stirrups takes place for lower load levels for $t=\infty$ than for $t=0$, being this difference particularly relevant in the case of the rigid girder TG2, where a relevant reduction of shear capacity is observed, as discussed next.

The analyses presented the following results of ultimate shear capacity: $V_{\mathrm{u}}(t=0)=221 \mathrm{kN}$ and $V_{\mathrm{u}}$ $(t=\infty)=209 \mathrm{kN}$ for TG1; $V_{\mathrm{u}}(t=0)=250 \mathrm{kN}$ and $V_{\mathrm{u}}(t=\infty)=173 \mathrm{kN}$ for TG2. Lower ultimate shear capacity is observed in the long term analysis $(t=\infty)$, being this difference more relevant for girder TG2. This is due to the loss of $V_{\mathrm{c}}$ caused by cracking of concrete due to the delayed restrained strains. The ratios of ultimate shear capacity $\left(V_{\mathrm{u}}\right)$ and concrete contribution to shear resistance $\left(V_{\mathrm{c}}\right)$ determined in the short- $(t=0)$ and long-term $(t=\infty)$ analyses are 
Fig. 6 Force in transversal reinforcement versus shear force at mid shear spans
Fig. 7 Ratios of short$(t=0)$ and long-term $(t=\infty)$ forces versus axial restraint: ultimate shear strength $V_{\mathrm{u}}$ and concrete contribution to shear resistance $V_{\mathrm{c}}$
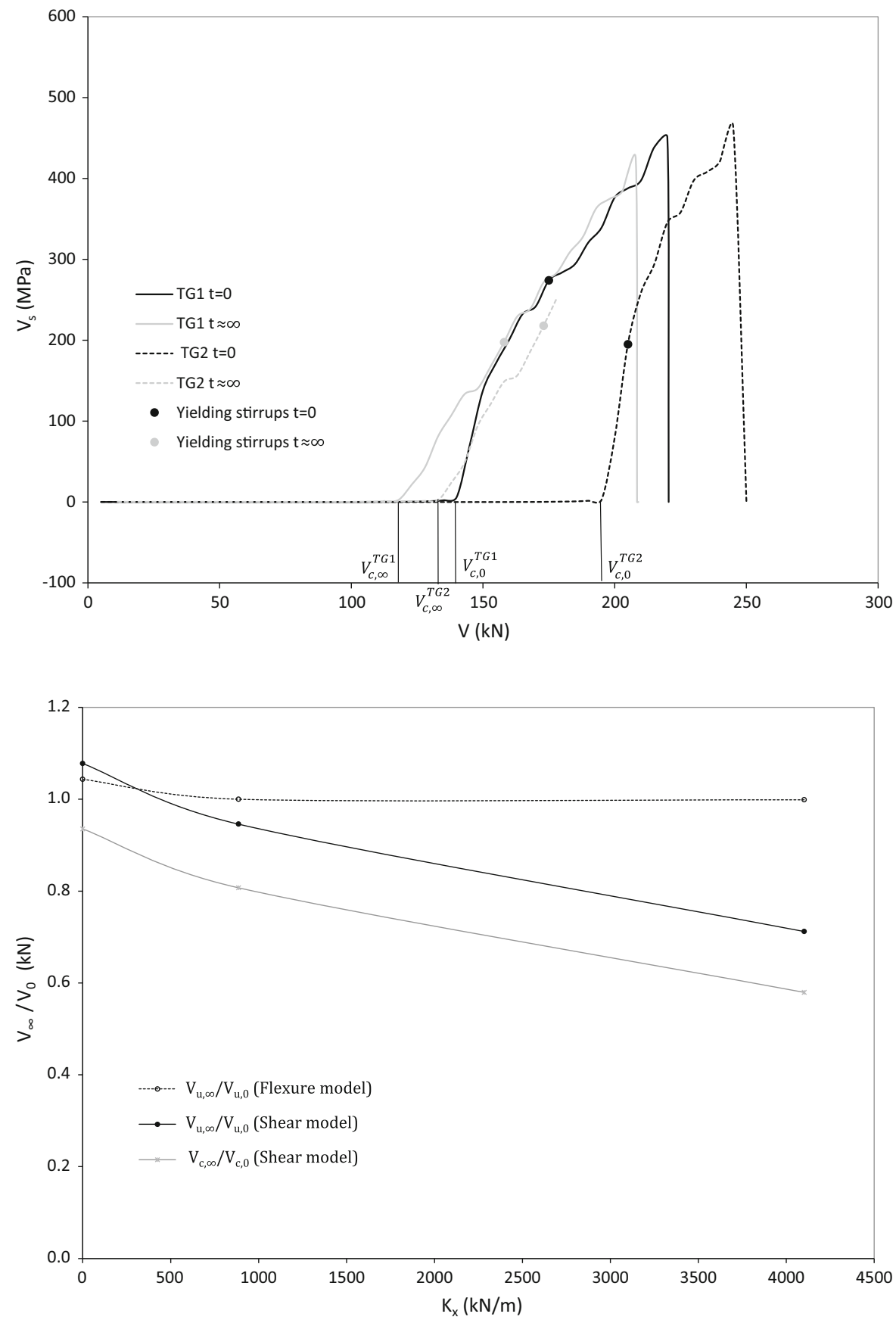

presented in Fig. 7 as function of axial restraint $K_{x}$. The results of the simple supported beam VSA1 analysed in Ferreira [39] are added to this graphs with $K_{x}=0$. The shear strength $V_{\mathrm{u}}$ diminishes in the long term with increasing $K_{x}$. This decrease is related with the loss of concrete capacity $V_{\mathrm{c}}$ to absorb shear stresses when pre-damage exists and higher restraints bring higher delayed strains and damage. The flexural model (only capable of capturing bending mechanisms) is impermeable to these aspects, predicting similar load capacities for all girders, despite their restraint levels or long-term effects. 


\section{Conclusion}

The interaction between time-dependent strains and shear resistant mechanisms of RC structural elements in service and ultimate limit states is observed and quantified in this paper.

A time-dependent model accounting for the effects of creep, shrinkage and temperature variations is incorporated in a shear-sensitive fibre beam model. The model is validated through experimental tests available in literature on diagonally pre-cracked RC beams under sustained load. The results of the shear model are compared with the ones of a traditional flexural beam model and with the experimental data. Shear was found relevant in the response of these beams. The shear model achieved a better fitting with the experimental data in comparison with the flexural model. It was observed that the influence of shear strains on the total deflection was relevant mainly in the instantaneous response. However, the share of shear deformation in the delayed deflections under constant loads was observed small compared to that of bending deformation.

Afterwards, the model is used to study the effects of transient restrained strains in the shear response of $\mathrm{RC}$ integral frames. A classical shear beam benchmark was adapted as part of transfer girders with different geometries of columns generating different magnitudes of restraint; a flexible and a rigid girder. Two analyses were performed for each girder: (i) a longterm analysis with loading (service load level), passage of time and loading again until failure and (ii) a short-term analysis with instantaneous loading until failure. A considerable decrease of the ultimate shear capacity was predicted in the long-term analyses: $(5.4 \%)$ for the flexible girder and $(28.8 \%)$ for the rigid girder. This decrease is consequence of cracking and tensile stresses brought by restraining strains in the time analysis, which were more relevant in the rigid girder. This damage decreases the concrete contribution to shear resistance, leading to the activation of the transversal reinforcement for lower loading levels. This phenomenon is only found in the shear mechanism. It differs from the bending ductile response, in which the time-dependent response in service does not influence the ultimate failure stage in terms of material nonlinearities.
The same set of analysis was performed with the flexural basic model, demonstrating its inadequacy to analyse structures that may be critical to shear.

The magnitude of the generated tensile forces varies with time, depending on the cracking state of the element; which differs from an externally applied load. This effect can be relevant in large integral structures. Accurate numerical assessments must account for the time-dependent strains and its influence in the ultimate shear resistance. It is worth noticing that the presented model is based on a relatively simple approach that allows fast modelling construction, hence it is particularly suitable for whole structural applications besides local analyses.

Acknowledgments The present research has been carried out with the support of the research project "Performance-baseddesign of partially prestressed concrete structures. Proposal of new design methodology, experimental verification and design criteria." (BIA2012-36848), co-financed by the Spanish Ministry of Economics and Competitiveness and European Funds for Regional Development (ERDF). The Postdoctoral Fellowship conceded by the Government of Catalonia (ref. 2013 PDJ 00022) to the first author is also gratefully acknowledged.

\section{Annex A}

Algorithm for computing the biaxial creep strain tensor (Eq. 4) through the approximation of the Dirichlet series (Eq. 8) using the hidden variables formulation of Bazant and $\mathrm{Wu}$ [34].

The time domain is divided into time steps $\Delta t_{n}$ that go from $t_{n}$ to $t_{n+1}$ and the Dirichlet series is approximated as:

$J\left(t^{\prime}, t-t^{\prime}, T\right) \Delta \underline{\sigma}_{n} \approx \sum_{i=1}^{m} \underline{A}_{i n}\left[1-e^{-\lambda_{i} \varphi(T) \Delta t_{n}}\right]$

with the increment of creep strain $\Delta \underline{\varepsilon}_{n}^{c}$ determined as:

$\Delta \underline{\varepsilon}_{n}^{c}=B_{e} \sum_{i=1}^{m} \underline{A}_{i n}\left[1-e^{-\lambda_{i} \varphi(T) \Delta t_{n}}\right]$

where $\underline{A}_{\text {in }}$ is the hidden state variable vector, given by:

$\underline{A}_{i n}=\underline{A}_{i n-1} e^{-\lambda_{i} \varphi(T) \Delta t_{n-1}}+\Delta \underline{\sigma}_{n} a_{i n}$

In the extended format, the determination of the biaxial strain increment due to creep involves computing the following expressions (considering $m=3$ ): 


$$
\begin{aligned}
& \left(\begin{array}{c}
\Delta \varepsilon_{n, x}^{c} \\
\Delta \varepsilon_{n, z}^{c} \\
\Delta \gamma_{n, x z}^{c}
\end{array}\right)=B_{\mathrm{e}} J\left(t^{\prime}, t-t^{\prime}, T\right)\left(\begin{array}{c}
\Delta \sigma_{n, x} \\
\Delta \sigma_{n, z} \\
\Delta \tau_{n, x z}
\end{array}\right) \\
& \left(\begin{array}{c}
\Delta \varepsilon_{n, x}^{c} \\
\Delta \varepsilon_{n, z}^{c} \\
\Delta \gamma_{n, x z}^{c}
\end{array}\right)=\left(\begin{array}{ccc}
1 & -v_{c} & 0 \\
-v_{c} & 1 & 0 \\
0 & 0 & 2\left(1+v_{c}\right)
\end{array}\right) \\
& \times\left(\begin{array}{c}
\sum_{i=1}^{m} \underline{A}_{i n, x}\left(1-e^{-\lambda_{i} \varphi(T) \Delta t_{n}}\right) \\
\sum_{i=1}^{m} \underline{A}_{i n, z}\left(1-e^{-\lambda_{i} \varphi(T) \Delta t_{n}}\right) \\
\sum_{i=1}^{m} \underline{A}_{i n, x z}\left(1-e^{-\lambda_{i} \varphi(T) \Delta t_{n}}\right)
\end{array}\right) \\
& \underline{A}_{i n}=\left(\begin{array}{c}
A_{i n, x} \\
A_{i n, z} \\
A_{i n, x z}
\end{array}\right) \\
& =\left(\begin{array}{c}
\underline{A}_{i n-1, x}\left(1-e^{-\lambda_{i} \varphi(T) \Delta t_{n-1}}\right)+\Delta \sigma_{n, x} a_{i, n} \\
\underline{A}_{i n-1, z}\left(1-e^{-\lambda_{i} \varphi(T) \Delta t_{n-1}}\right)+\Delta \sigma_{n, z} a_{i, n} \\
\underline{A}_{i n-1, x z}\left(1-e^{-\lambda_{i} \varphi(T) \Delta t_{n-1}}\right)+\Delta \tau_{n, x z} a_{i, n}
\end{array}\right)
\end{aligned}
$$

In order to start the analysis $(n=1)$ the first hidden variable vector $A_{i l}$ is given as

$\underline{A}_{i 1}=\left(\begin{array}{c}A_{i 1, x} \\ A_{i 1, z} \\ A_{i 1, x z}\end{array}\right)=\left(\begin{array}{c}\Delta \sigma_{1, x} a_{i, 1} \\ \Delta \sigma_{1, z} a_{i, 1} \\ \Delta \tau_{1, x z} a_{i, 1}\end{array}\right)$

Determination of the creep compliance function is accomplished by fitting, through the least square method, its aging scale parameters $a_{i}$ to the empirical expression considered. Constants $\lambda_{i}$ are set as $10^{-i}$ $\left(\lambda_{1}=0.1, \lambda_{2}=0.01 ; \lambda_{3}=0.001\right)$ and three terms on the Dirichlet series are considered $(m=3)$. From Eq. (8) the following system of simultaneous equations is obtained

$$
\begin{aligned}
& \left(\begin{array}{lll}
1-e^{-\lambda_{i} \Delta t_{n}} & 1-e^{-\lambda_{i} \Delta t_{n}} & 1-e^{-\lambda_{i} \Delta t_{n}} \\
1-e^{-\lambda_{i} \Delta t_{n}} & 1-e^{-\lambda_{i} \Delta t_{n}} & 1-e^{-\lambda_{i} \Delta t_{n}} \\
1-e^{-\lambda_{i} \Delta t_{n}} & 1-e^{-\lambda_{i} \Delta t_{n}} & 1-e^{-\lambda_{i} \Delta t_{n}}
\end{array}\right)_{n \times m}\left(\begin{array}{c}
a_{1 n} \\
a_{2 n} \\
a_{3 n}
\end{array}\right)_{m \times 1} \\
& =\left[\begin{array}{c}
J\left(t^{\prime}, t_{1}-t^{\prime}\right) \\
J\left(t^{\prime}, t_{2}-t^{\prime}\right) \\
J\left(t^{\prime}, t_{3}-t^{\prime}\right)
\end{array}\right]_{n \times 1}
\end{aligned}
$$

which is solved to determine the values of $a_{i}$ that better fit the empirical curve. Typical values for $a_{i}$ are around $1 \times 10^{-7}$ and $2 \times 10^{-7}$.

\section{References}

1. Chan E (1982) Nonlinear geometric, material and time dependent analysis of reinforced concrete shells with edge beams. Structural Engineering and Structural Mechanics, Department of Civil Engineering, University of California, Berkeley

2. Marí ARB (2000) Numerical simulation of the segmental construction of three dimensional concrete frames. Eng Struct 22:585-596

3. Van Greunen J (1979) Nonlinear geometric, material and time dependent analysis of reinforced and prestressed concrete slabs and panels. Structures and Materials Research, Department of Civil Engineering, College of Engineering. University of California, Berkeley

4. ASCE-ACI Commitee 445 on Shear and Torsion (1998) Recent approaches to shear design of structural concrete. J Struct Eng 124(12):1375-1417

5. Zararis PD, Zararis IP (2009) Shear strength of reinforced concrete slender beams with or without axial forces-a generalized theory. ACI Journal 106(6):782-789

6. Marí A, Bairán JM, Cladera A, Oller E, Ribas C (2015) Shear-flexural strength mechanical model for the design and assessment of reinforced concrete beams. Struct Infrastruct Eng 11(11):1399-1419

7. Ferreira D, Bairán JM, Marí A (2015) Efficient 1D model for blind assessment of existing bridges: simulation of a full scale loading tests and comparison with higher order continuum models. Struct Infrastruct Eng 11(10):1383-1397

8. Bairán J, Marí A (2007) Shear-bending-torsion interaction in structural concrete members: a nonlinear coupled sectional approach. Arch Comput Methods Eng 14(3):249-278

9. Ceresa P, Petrini L et al (2010) Flexure-shear fiber beamcolumn elements for modeling frame structures under seismic loading — state of the art. J Earthq Eng 11(1):46-88

10. Mazars J, Kotronis P et al (2006) Using multifiber beams to account for shear and torsion. Applications to concrete structural elements. Comput Methods Appl Mech Eng 195:7264-7281 
11. Valipour HR, Foster SJ (2013) A mechanistic 1D finite element model for nonlinear analysis of FRP-strengthened reinforced concrete beams. Adv Struct Eng 16(12):1989-2004

12. Vecchio FJ, Collins MP (1988) Predicting the response of reinforced concrete beams subjected to shear using the modified compression field theory. ACI J 85(3):258-268

13. Spacone E, Filippou FC et al (1996) Fibre beam-column model for non-linear analysis of R/C frames: part I. Formulation. Earthq Eng Struct Dyn 25:711-725

14. Petrangeli M, Pinto PE et al (1999) Fiber element for cyclic bending and shear of RC structures. I:Theory. J Eng Mech 125(9):994-1009

15. Güner (2008) Performance assessment of shear-critical reinforced concrete plane frames. Department of Civil Engineering. Toronto, University of Toronto. $\mathrm{PhD}$ Thesis

16. Mohr S, Bairán J, Marí A (2010) A frame element model for the analysis of reinforced concrete structures under shear and bending. Eng Struct 32(12):3936-3954

17. Ferreira D, Bairán JM, Marí A, Faria R (2014) Nonlinear analysis of RC beams using a hybrid shear-flexural fibre beam model. Eng Comput 31(7):1444-1483

18. Ferreira D, Bairán JM, Marí A (2016) Shear strengthening of RC beams by means of vertical prestressed reinforcement. Struct Infrastruct Eng 12(3):394-410

19. Bazant ZP, Carol I (1993) Fifth RILEM Internation Symposium on Creep and Shrinkage of Concrete (ConCreep-5). Barcelona, Spain 6-9 September 1993. Materials and Structures 27(6): 370-372

20. Bazant ZP, Guang-Hua J (2008). Comprehensive database on concrete creep and shrinkage. S. E. R. N. 08-3/A210c, Infrastructure Technology Institute. McCormick School of Engineering and Applied Science. Northwestern University. Evanston, Illinois 60208, USA

21. Gopalakrishnan KS, Neville A et al (1969) Creep poisson's ratio of concrete under multiaxial compression. ACI J 66(90): 1008-1020

22. Gopalakrishnan KS, Neville A et al (1970) A hypothesis on mechanism of creep of concrete with reference to multiaxial compression. ACI J 67(3):29-35

23. Kim JK, Kwon SH et al (2006) Analytical studies on creep of sealed concrete under multiaxial stresses using a microplane model. Mag Concr Res 58(1):9-20

24. Bazant Z (1988) Mathematical modeling of creep and shrinkage of concrete. Wiley, New York
25. Illston JM, Jordaan IJ (1972) Creep prediction for concrete under multiaxial stress. ACI J 69(14):158-164

26. Kim JK, Kwon SH et al (2005) Experimental studies on creep of sealed concrete under multiaxial stresses. Mag Concr Res 57(10):623-634

27. Vecchio FJ, Collins MP (1986) The modified compressionfield theory for reinforced concrete elements subjected to shear. ACI J 83(2):1357-1417

28. Kupfer H, Hilsdorf HK et al (1969) Behavior of concrete under biaxial stresses. ACI J 66(8):656-666

29. Cervenka V (1985) Constitutive model for cracked reinforced concrete. ACI J 82(6):877-882

30. Kabir AF, Scordelis AC (1976) Non-linear analysis of reinforced concrete panels, slabs and shells for time dependent effects, Ph D Dissertation. Division of Structural Engineering and Structural Mechanics, Univ. of California, Berkeley, UC-SESM Report No 76-6, December 1976

31. Kang YI, Scordelis A (1982) Nonlinear analysis of prestressed concrete frames. ASCE J Struct Div 106:445-462

32. Mazzotti C, Savoia M (2003) Nonlinear creep damage model for concrete under uniaxial compression. J Eng Mech 129(9):1065-1075

33. Chong KTC, Foster SJ et al (2008) Time-dependent modelling of RC structures using the cracked membrane model and solidication theory. Comput Struct 86:1305-1317

34. Bazant ZP, Wu ST (1973) Dirichlet series creep function for aging concrete. J Eng Mech 99(2):367-387

35. CEB-FIP (1992). Model Code 1990, design code. London

36. Bazant Z (1983) Comment on orthotropic models for concrete and geomaterials. J Eng Mech 109(3):849-865

37. Zienkiewicz OC (1977) The finite element method. McCraw-Hill, London

38. Nie J, Cai CS (2000) Deflection of cracked RC beams under sustained loading. J Struct Eng 126(6):708-716

39. Ferreira D (2013) A model for the nonlinear, time-dependent and strengthening analysis of shear critical frame concrete structures. Departament D'Enginyeria de la Construcció. Barcelona, Universitat Politècnica de Catalunya. Escola Tècnica Superior d'Enginyers de Camins, Canals i Ports. PhD Thesis

40. Vecchio FJ, Shim W (2004) Experimental and analytical reexaminations of classic concrete beam tests. J Struct Eng $130(3): 460-469$ 